\title{
The financial burden of cancer in a poor income country:Tanzania
}

\section{Opinion}

Health is generally expensive in the world today and the high costs keep surging with each passing day. In cancer, the story is no different and the financial weight is on the shoulders of not only the patient but also on the family and the society as a whole. The costs arise from tests and hospital visits but a huge chunk of it are due to the treatment. And since cancer in the recent years has evolved to a chronic illness, the bills are more than ever before. But of course as humans the heaviest cost is incurred at the end of the battle when a soul that was a brain winner of a family or society passes on.

Back in 2010, the annual global costs of cancer was estimated at a staggering \$1.16 trillion. This figure was reached after considering the economic value of the lives lost and disability caused and the direct costs associated with prevention and treatment of the disease. It also important to note that Non communicable Diseases with cancer included, already have shown to pose an alarming economic burden and this burden is likely to turn into a staggering one in the next twenty years. It has been estimated that cancer together with other NCDs combined are responsible of an output loss of US\$ 47 trillion representing 75\% of global GDP IN 2010 (US\$63 Trillion).

In Tanzania there have not been any attempts to quantify the costs of this deadly disease to our young nation. One would argue that the failure to estimate such costs is the lack of big data, which has much more repercussions in when consideration a bigger context. The direct cost that is easier to point is the 7.2 Billion Tshs that was allocated for the only state run cancer center, Ocean Road Cancer Institute for the year $2015 / 16$. Though Only $11 \%$ of the funds were allocated, this does not mean that the calculated costs the nation incurred in that year were in any way lessened. It's possible that the failure to deliver the funds resulted in less cancer preventive programs from being rolled out and hence more cancer incidences in the subsequent years. In addition possibly more deaths were never prevented to lack to lack of funds to buy the drugs.

The picture seen at the Tanzanian Ocean road Institute by far is just the tip of the iceberg due to the fact that not all cancer patients end up at the institute. The Tanzanian ministry of health estimates that $95 \%$ of cancer patients in the country die at home and only the remaining 5\% in the hospitals scattered across. Hence the magnitude of the financial burden of cancer in the country should go beyond the institute. As I have pointed out before due to lack of big data on cancer and absence of an active cancer registry, near correct estimates of the impact of this disease on our economy will continue to be elusive.

Attempting to understand the costs of cancer treatment and those due to deaths, one can refer to the WHO report of 2002 which estimated there were approximately 21000 new cases of cancer. Among the new cases, $43 \%$ died before they reached the age of 60 . Since not of these patients saw the corridors of ORCI, the costs were felt directly by the patient and the families. For example for a patient leukemia he may
Volume 9 Issue I - 2018

\author{
Heri M Tungaraza \\ Oncologist, Muhimbili National Hospital,Wenzhou medical \\ University, Tanzania \\ Correspondence: Heri M Tungaraza MD, Mmed-Oncology, \\ Muhimbili National Hospital,Wenzhou medical University, \\ Tanzania,Email tungarazah@gmail.com
}

Received: December 15, 2017 | Published: January 31, 2018

need approximately not less than 500,000 each month for about six months to treat the disease. With the introduction of novel drugs that work together with the old chemotherapy and have shown to increase better treatment outcome, the prices are even higher with a single dose ranging from 2 million to 8 million. Subjecting these ridiculous prices to a poor Tanzania is like unleashing terror to their already hopeless life. The National Health Insurance Fund covers about 22.8 of the 44 million Tanzanians with the private health insurers covering just about $1 \%$, hence most of the financial burden is felt by individuals directly.

For long it has been believed that for a nation to prosper its people must be health so that they keep driving the economy of the country. A country with a dying people won't stand a chance for survival. As the new president moves in with an agenda of cost cutting, I call upon the rest of the government to take the necessary steps to abate the cancer epidemic before its financial toll becomes a stumbling block on our path to an economic giant. But before these efforts are put into play, we need to put on the table the actual costs of this monster to our nation.

\section{Conflicts of interest}

None.

\section{Acknowledgements}

None.

\section{Funding}

None. 